\title{
Relationship between room characteristics and speech intelligibility in contemporary churches in Malaysia
}

\author{
Nazli bin Che Din*, Lew Han Yong and Asrul Sani Abdul Razak \\ Department of Architecture, Faculty of Built Environment, \\ University of Malaya, 50603 Kuala Lumpur, Malaysia, \\ *Email: nazlichedin@um.edu.my
}

\begin{abstract}
Church as a place of worship has a unique architectural style and is of great social importance for the Christian community. The church geometric configurations vary from classical cruciform to octagonal-shaped plan. Acoustically, some geometric shapes work much better than others while others can be downright awful. The objective of this study is to investigate the relationship between room characteristics and speech intelligibility in church acoustics. At the first stage of this study, a total of eight existing churches in Malaysia were identified and then grouped into three types, i.e. fan, rectangular, and cruciform. Then, a fan-shaped room model was selected to be simulated in detail for sectional studies. Nine different ceiling shapes were constructed for evaluation purposes. All the selected churches were modelled using the 3D modelling software, SketchUp and then exported into the commercial acoustic software, ODEON, for acoustical simulation. The simulated results were then compared to the parameter of speech transmission index (STI). The results indicate that there was no specific relationship of the STI with all three groups of room types. However, a direct relationship between the STI means value with its room volume as well as its distance between sound source and receiver points can be observed, whereby F3 being the highest average value of STI (0.44) whereas R2 showed the lowest average value of STI (0.30). All room models generally achieved 'fair' STI values at the front position of the altar but the STI values drop into 'poor' when the distance exceeds over than $6.5 \mathrm{~m}$. In the second stage, the results obtained show a direct relationship between the STI means values with the lower ceiling height above the sound source and a shorter distance between the sound source and its surrounding walls that may provide higher speech intelligibility due to the strong early sound energy. This paper provides fundamental data on the relationships between room characteristics and speech intelligibility, which would then help with future refinements.
\end{abstract}

Keywords: Room shape; speech intelligibility; church.

\section{INTRODUCTION}

Churches have unique architectural style and typically serve as a place of worship for the Christian community. Modern worship services demand active interaction and visual linkage between the stage (the preacher) and congregation (the public). The main goal of a church service is to deliver God's message to all participants in the church. The preacher primarily leads the service with speech $[1,2]$. In addition, the listeners in the worshipping space have a dual function. They are not only sound receivers but also sound sources. At first, as the sound receivers, it is essential for them to clearly receive speech sound from 
the preacher and the singing sound from the musical performance group. As the sound sources, the congregational singing is the most important church music because congregational singing is the way participants respond to the God's message [3]. Thus, it is essential to produce adequate speech sound so that it can be heard clearly at any seating positions in the building, otherwise, the participants may feel a sense of alienation. Everyone in the church service must be in an equal acoustical environment because everyone is equal in the house of God [4].

Looking at the historical context in the western European history, from the middle ages through the Renaissance, the construction of Roman Catholic cathedrals became larger by the scale and as a result has high reverberant acoustic environments for liturgical music and chants. However, the early synagogues which emphasized sermons and scriptural readings required less reverberant spaces than the medieval cathedrals. The Protestant Reformation began in early 1517. It was a movement which broke up the institutional unity of the church in the Western Europe and established the third great branch of Christianity. Since the Reformation time period, high speech intelligibility has become a more common and important requirement for the church service than in the medieval cathedral [2]. In the early 1940s, some churches were built in isolated places and it was not necessary to worry about acoustic problems such as noises from outside activities, mechanical installations or even interior human activities [5]. After the World War II, many countries such as Korea and Japan which experienced terrible war needed to rebuild worshipping spaces and started to use sound reinforcement systems [6]. At first, this application seemed to be financially successful because inexpensive sound reinforcement systems were used. However, people started to realize that they did not have adequate acoustical equipment [5].As there were increasing number of service participants, much bigger organ facility and bigger room size were required. Therefore, the architectural aspects of the church design also started to change. At the same time, many types of mechanical equipment and new musical instruments such as electronic organs and synthesizers were installed while traditional instruments like the pipe organ and piano were still in use. These made it possible to start to invest in the acoustical quality of churches and establish the need for acoustic experts to assist in achieving not only proper architectural designs for natural acoustics but also the proper installation of the sound reinforcement systems.

Modern churches involve many different types of functions based on their liturgical style. Modern worship services often require active interaction between the preacher, performing musical group and congregation. The main goal of worship service is to provide God's message to all participants in the service. Thus, it is necessary for the space in the church to have good acoustics to allow good verbal and musical communication travel. The highly reverent acoustics of a cathedral are well suited to the organ and Gregorian chants. However, the simultaneous need for high speech intelligibility is also important for the cathedral style of church. On the other hand, an evangelical style of the church has as large volume as a cathedral but contemporary popular music is usually played with an electronic organ [2]. Contemporary church auditoriums require various functions. A church space is no longer only for worshipping but also many other activities such as classes, meetings, and recreation. These different functions need different acoustical conditions. Each room should provide optimum acoustic parameters for the functions it will have. Acoustically, churches have a complex mission to meet the requirements of both speech and music, which often seem incompatible. The acoustics for the church music requires enough reverberant sound for instruments and congregational singing but speech sound requires only about one-half of 
the reverberation time for the church music because it must be heard clearly to be understood. Therefore, it is not easy to satisfy the acoustical requirements for these two environments at the same time. Ideally, one should not be sacrificed for the other [3]. Good acoustic is central to the function of many occasions in the church; it is essential that architects consider the acoustical properties in the early stage of the design process, such as geometrical form and material used. Acoustics in the church have been the focus of research groups in the European countries [7-12]; however, the amount of available research information on the church acoustics is immeasurably less in Malaysia, in particular, the studies of contemporary church design and how space and form affect acoustical performance.

In the church design, fundamental room shape i.e. fan, rectangular, steeped and reverse fan shapes and its spatial volume represent the primary design considerations to provide the optimum acoustic environment. Curved surfaces can cause the destructive focus of sound and therefore, should be avoided if it is not properly treated with sound diffusing materials [13]. Having walls in the wrong place or at an awkward angle can cause acoustic problems such as standing waves, flutter echo, sound focusing and intensive late reflections. Long and flat parallel walls cause undesirable flutter echo which can ultimately reduce speech intelligibility. Spatial volumetric separation by alcoves, archways, and moveable and fixed objects, which are seen in many older churches, may also diminish the effectiveness of early arriving sound energy and weaken the speech intelligibility. Wide fan shapes and semi-circular floor plan usually do not provide strong, early lateral reflections because the side walls are too far apart. Unless overhead sound reflectors can be used to overcome the absence of lateral sound reflected from walls, the playing of musical instruments will be heard as very distant and lack of full tone quality. This geometrical consideration must be given not only in the design of the building floor plan but also in the design of the section as well. Also, in the prediction of acoustical simulation, the dimensional ratios of the room length to its width as well as the ratios of the room height to width are important considerations in the design [14-16]. At present, church geometric configurations vary from classical rectangular shaped to the octagonalshaped plan. The purpose of this study is to investigate the relationship between the room characteristics and speech intelligibility in the selected contemporary churches using computer modelling and simulation analysis, particularly on spatial distribution patterns of speech intelligibility in the absence of sound reinforcement systems. The results were then compared with the parameter of Speech Transmission Index (STI).

\section{METHODOLOGY}

\section{Simulation 1: Room Shape vs. Speech Intelligibility}

The primary purpose of this study is to investigate the relationship between the room geometrical shape and speech intelligibility in the church in the absence of sound reinforcement system. The selection sample of a representative of the contemporary churches in Malaysia was based on shape, layout and other factors contributed to the final selection in addition to the architectural drawing availability. Eight churches in Perak, Malaysia were selected from three major room shapes: rectangular, fan, and cruciform. The categorization of these shapes was taken from a review of numerous church projects done by a local architect firm in Perak. 


\section{Simulation 2: Sectional Studies vs. Speech Intelligibility}

In the second stage of this study, the better-simulated result from the previous section of the selected shape of the room model was chosen to be further analysed for the sectional studies. The modification of ceiling shapes was designed accordingly to identify the impact of the ceiling profile onto the acoustical performance. All of the modelled rooms that have identical room plan and seating capacity have been set as the originally shaped model.

\section{Model Construction and Simulation}

The building and modelling of the 3D digital models were carried out using SketchUp, an off the shelf and affordable 3D software modelling tool. The complex architectural details such as an ornament, cornice, framing etc. were omitted because they do not produce any strong early reflections to the receiver [15]. Table 1 presents data summarizing the main physical characteristics of the eight selected churches. In the next stage, the architectural digital models of these churches were then simplified for the purpose of acoustical computational analysis using the commercial software of ODEON Room Acoustic version 12.10 Industrial [16]. When assigning a boundary condition in ODEON, its validity must be checked. The performed simulation involved verification process whether data is consistent and in the correct format. This involves the water tightness test of the room through the use of the $3 D$ Billiard window. Water tightness test is to check whether the room model and boundary condition are completely enclosed as shown in Figure 1. This is to ensure the accuracy of the simulation process.

In ODEON, the selection of materials can be assigned directly from the material library. Each individual surface of the digital model must be assigned with material before any simulations can be performed. In this study, the materials used for each church were standardized in order to provide consistency of condition in each room model. Table 2 shows the assigned materials of churches and their related absorption characteristics used in this study.

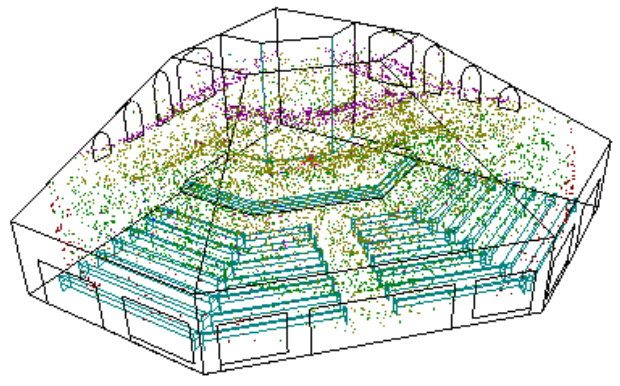

(a)

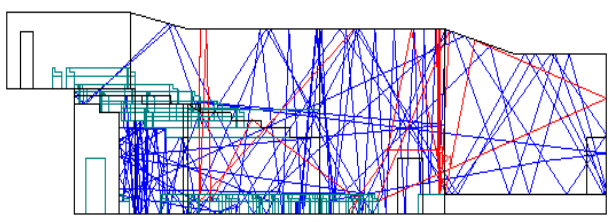

(b)

Figure 1. Example of water tightness test; (a) 3D billiard in room model of F3 and (b) 3D Investigate Rays in room model of F2.

\section{Sound Sources and Receiver Points}

Before the simulations were carried out by ODEON, the sound source and receiver were defined in an orderly sequence as shown in Table 3. In this study, a single point of naturally raised sound (BB93_RAISED_NATURAL.SO8) was used as the sound source. 
Table 1. Basic characteristics and description of each room model.

\begin{tabular}{|c|c|c|c|c|c|c|}
\hline $\begin{array}{c}\text { Churc } \\
\text { h } \\
\text { Abbrv. }\end{array}$ & 3D Room Model & $\begin{array}{c}\text { Type } \\
\text { (Shape) }\end{array}$ & $\begin{array}{c}\text { Volume } \\
, \mathbf{m}^{\mathbf{3}}\end{array}$ & $\begin{array}{c}\text { Max } \\
\text { Height } \\
\text {, m } \\
\end{array}$ & $\begin{array}{c}\text { Area, } \\
\mathbf{m}^{2}\end{array}$ & $\begin{array}{c}\text { Numbe } \\
\text { r of } \\
\text { seat }\end{array}$ \\
\hline F1 & & Fan shape & 1617.5 & 6.89 & $\begin{array}{c}306.2 \\
6\end{array}$ & 300 \\
\hline F2 & & Fan shape & 3638.5 & 6.91 & $\begin{array}{c}473.9 \\
3\end{array}$ & 620 \\
\hline F3 & & Fan shape & 1422.3 & 6.95 & $\begin{array}{c}290.6 \\
5\end{array}$ & 270 \\
\hline R1 & & $\begin{array}{l}\text { Rectangula } \\
\text { r shape }\end{array}$ & 4153.0 & 7.32 & $\begin{array}{c}564.0 \\
3\end{array}$ & 750 \\
\hline $\mathbf{R 2}$ & & $\begin{array}{l}\text { Rectangula } \\
\text { r shape }\end{array}$ & 7286.4 & 10.10 & $\begin{array}{c}845.9 \\
3\end{array}$ & 1150 \\
\hline $\mathbf{R 3}$ & & $\begin{array}{l}\text { Rectangula } \\
\text { r shape }\end{array}$ & 2629.4 & 8.08 & $\begin{array}{c}368.6 \\
6\end{array}$ & 350 \\
\hline C1 & & Cruciform & 2026.8 & 8.49 & $\begin{array}{c}326.0 \\
2\end{array}$ & 295 \\
\hline C2 & & Cruciform & 2026.8 & 8.49 & $\begin{array}{c}326.0 \\
2\end{array}$ & 295 \\
\hline
\end{tabular}


The sound source was placed at $1 \mathrm{~m}$ set back from the edge of the altar area and raised $1.5 \mathrm{~m}$ from the altar floor. The directivity of this sound source was derived from Egan [17]. Then, the receiver locations were occupied uniformly across the whole area of the church room as the example shown in Figure 2.

Table 2. Sound absorption coefficient of materials used in this study.

\begin{tabular}{llllll}
\hline & & \multicolumn{4}{c}{ Frequency } \\
\cline { 3 - 6 } No. & Building component and materials & $\mathbf{2 5 0}$ & $\mathbf{5 0 0}$ & $\mathbf{1 0 0}$ & $\mathbf{2 0 0 0}$ \\
\hline \multirow{2}{*}{$\begin{array}{l}\text { Floor: Ceramic tiles. Perforation = 12\%, Mineral } \\
\text { wool in cavity }\end{array}$} & 0.44 & 0.68 & 0.79 & 0.56 \\
\hline 2 & $\begin{array}{l}\text { Walls: Smooth brickwork, 10mm depth pointing, pit } \\
\text { sand mortar }\end{array}$ & 0.09 & 0.12 & 0.16 & 0.22 \\
\hline 3 & $\begin{array}{l}\text { Ceiling: Perforated 27mm gypsum board (16\%), d= } \\
\text { 4.5mm 300mm from ceiling }\end{array}$ & 0.55 & 0.60 & 0.90 & 0.86 \\
\hline 4 & Concrete column: Concrete block, painted & 0.05 & 0.06 & 0.07 & 0.09 \\
\hline 5 & Chair: Audience on wooden chairs, 1 per sq.m. & 0.24 & 0.56 & 0.69 & 0.81 \\
\hline 6 & Window: Glass, Ordinary window glass & 0.25 & 0.18 & 0.12 & 0.07 \\
\hline 7 & Door: Solid wooden door & 0.10 & 0.06 & 0.08 & 0.10 \\
\hline 8 & Railing: Solid glass block & 0.02 & 0.02 & 0.02 & 0.02 \\
\hline
\end{tabular}

Table 3. Basic information on the simulation settings fixed in ODEON.

\begin{tabular}{lllll}
\hline No. of sound source & $:$ & 1 (set at $1.5 \mathrm{~m}$ high) & \\
\hline Sound source type & $:$ & BOSE & BB93_NORMAL_NATURAL_S08; & Total \\
& & power: $68.4 \mathrm{~dB}(\mathrm{~A})$ & \\
\hline No. of multi-point & $:$ & \multicolumn{4}{c}{ Grid Points (all set at 1.5 m high) } \\
\cline { 2 - 5 } source & & F1: 26 & R1: 30 & C1: 24 \\
& & F2: 24 & R2: 30 & C2: 24 \\
& & F3: 16 & R3: 26 & \\
\hline
\end{tabular}

\begin{tabular}{ll}
\hline $\begin{array}{l}\text { Impulse response } \\
\text { length }\end{array}$ & $:$ between $1660 \mathrm{~ms}$ to $6020 \mathrm{~ms}$ \\
\hline
\end{tabular}

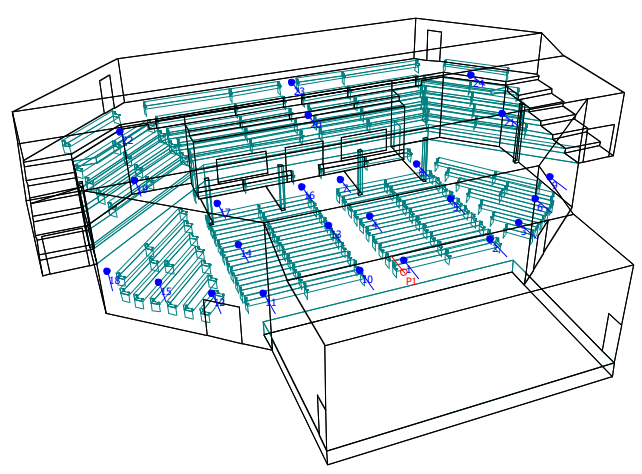

(a)

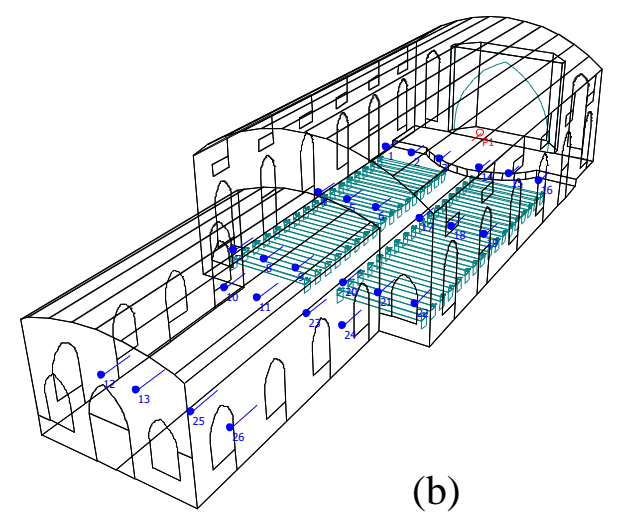

(b)

Figure 2. Example of sound source location (red) and receiver points (blue); (a) room model of F2 and (b) room model of R3. 


\section{Speech Transmission Index}

Speech transmission index (STI) has been selected as an indicator to measure the speech transmission quality or as a speech intelligibility assessor. As shown in Figure 3, STI is a well-established objective measurement predictor that determines how the characteristics of the transmission channel affect speech intelligibility and representation as numeric values from $0=$ bad to $1=$ excellent. On this scale, an STI of at least 0.5 is desirable for most applications. Barnett [18] proposed to use a reference scale, the Common Intelligibility Scale (CIS), based on a mathematical relation with STI (CIS $=1+\log (\mathrm{STI}))$.

\begin{tabular}{|cccccccc|}
0 & STI & 0.3 & \multicolumn{2}{c}{0.45} & 0.6 & 0.75 & 1.0 \\
\hline & BAD & \multicolumn{2}{c}{ POOR } & FAIR & GOOD & \multicolumn{2}{c|}{ EXCELLENT } \\
\hline 0 & CIS & 0.48 & 0.65 & 0.78 & 0.88 & 1.0
\end{tabular}

Figure 3. Speech Transmission Index [19].

\section{RESULTS AND DISCUSSION}

\section{Simulation 1: Room Shape vs. Speech Intelligibility}

Eight churches from three different room shapes were used to evaluate the relationship between room shape and speech intelligibility by using ODEON. The results were compared with the parameter of STI. Figures 4(a) and (b) present the examples of graphic visualization for STI distributions in room model of F2 and R3, respectively. The intensity of visualization was expressed in RGB scale within a given range between 0.6 and 0.35 . In these figures, both the STI distributions for room models clearly showed that the intensity levels became dark blue towards the longer distance. The same basic tendencies can also be observed in other room models. In order to provide and ensure a compact and convenient presentation for the reader, all the results are represented in the numerical approach for average STI of all receiver points in all room models. As depicted in Figure 5, F3 had the highest average value of STI, which was 0.44 and R2 showed the lowest average value of STI, which was 0.30. However, when the STI values were compared at each position in the room model, the highest STI value of 0.67 was found at the front positions of the F1 (fan-shaped room). All room models generally achieved fair STI values at the front positions of the altar (sound source) but the STI values dropped into poor rating when the distance between sound source and receivers exceeds over $6.5 \mathrm{~m}$. The STI value decreased as the distance of receiver points increased from the sound source. Based on the result, none of the 3D models have achieved a good rating of STI overall.

There is a direct relationship between the STI means value with its volume as well as its distance between the sound source and receiver points. The simulated results show the tendency of the larger the volume is, the lower the average value of STI becomes. For example, R2 has the lowest STI value with the highest volume. Poor speech intelligibility may be resolved by having ceiling treatments and installing sound reinforcement system. F1, F3, C1, and C2 have better STI values due to the lower ceiling height. These room models may not only have a short distance between the sound source and its surrounded walls but also sloped ceilings above the sound source.It can be generally concluded that the lower ceiling height above the sound source and shorter distance between the sound source and its surrounding walls may provide higher speech intelligibility in the most parts of the room because they will help to provide strong early sound energy reflections. However, if the room ceiling height is not adequate enough to distribute the early 
reflections to the rear room, speech intelligibility will be poor relative to the other parts of the room [20].

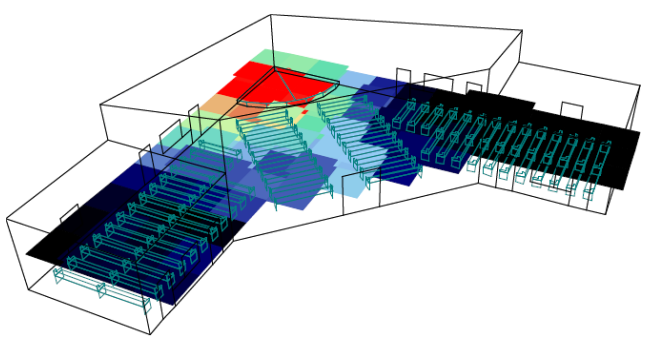

(a)

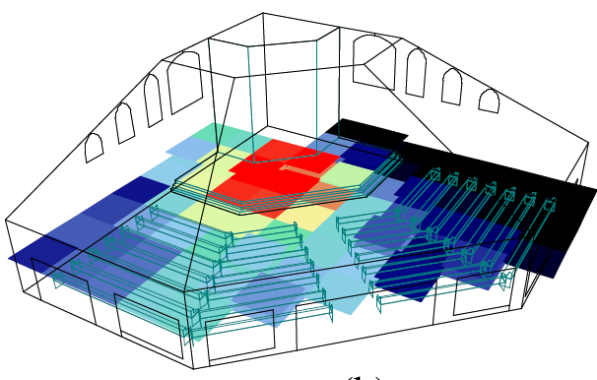

(b)

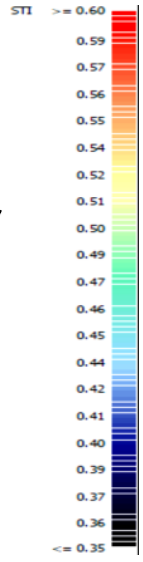

Figure 4. Example of STI distribution in room models; (a) F2 and (b) R3.

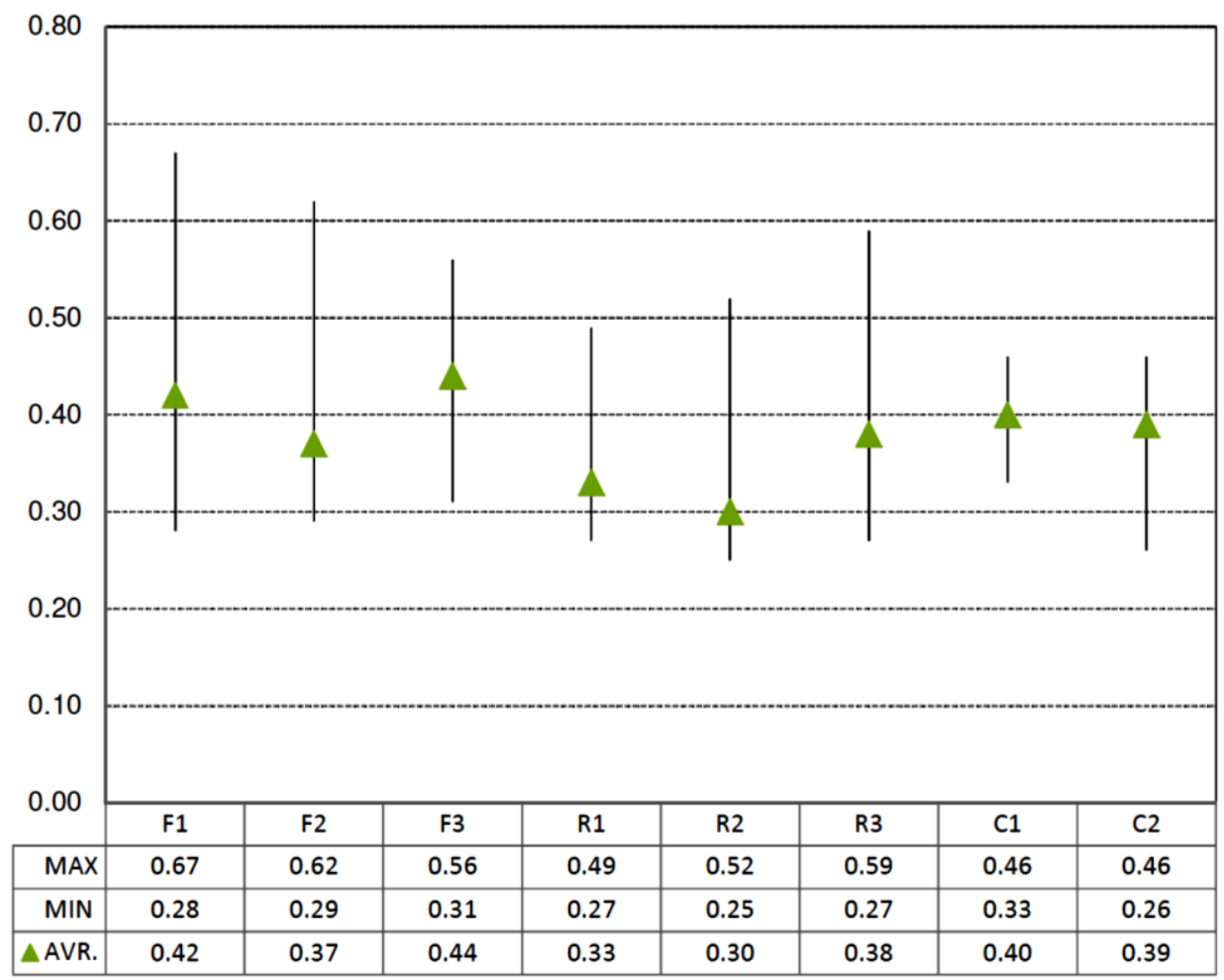

Figure 5. Comparison of Speech Transmission Index, STI for each room model.

\section{Simulation 2: Section Studies vs. Speech Intelligibility}

In this section, one type of the fan-shaped room models, F3, was selected to be simulated for the sectional studies based on the highest value of STI as presented in the previous section. Nine different ceiling shapes were designed depending on the ceiling shape modifications as illustrated in Figure 6. The main purpose of the simulations in this section is to evaluate the impact of ceiling profiles on the speech intelligibility. All of these sectional cut-outs have identical room plan and a seating capacity of 270 seats as the original fan-shaped model. The materials, sound source and receivers' positions used 
in the computer simulations remained the same.Based on the results obtained in Table 4; FS1, FS2, FS3, and FS4 have generally improved on the STI values compared to the original room model. However, when the STI values were compared at each position in the room model, the highest STI value of 0.58 was found to be located at the front position of FS1 and FS2. All room models achieved fair STI value occurring at the front position of the altar (sound source) but the similar tendency of STI values dropped into poor rating when the distance between sound source and receivers exceeded $6.5 \mathrm{~m}$ as found in the previous section.

In addition, a direct relationship can be observed between the STI means values with its ceiling profile above the sound source. FS1, FS2, FS3, and FS4 have better STI value due to their lower ceiling above the sound source. The lower ceiling height above the sound source and shorter distance between the sound source and its surrounding walls may provide a higher speech intelligibility in most parts of the room because they help to provide strong early sound energy reflections. However, FS5, FS6, FS7, FS8, and FS9 have lower STI values compared to the original room model because the ceiling characteristics have been lifted up and flattened the ceiling of the room. Even though some improvement on the STI values can be observed in the simulated STI, they can be considered as less significant based on no enhancement towards better STI rating.

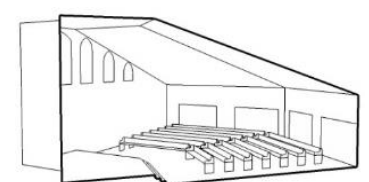

O: Original room model

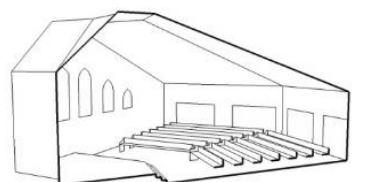

FS1: Single-sloped ceiling $\left(45^{\circ}\right)$ above sound source

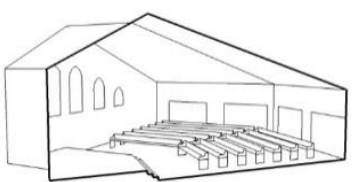

FS2: Single-sloped ceiling $\left(30^{\circ}\right)$ above sound source

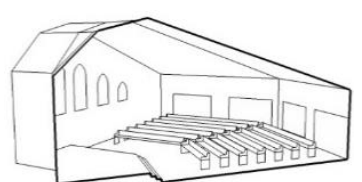

FS3: Double-sloped ceiling $\left(45^{\circ} \& 30^{\circ}\right)$ above sound source

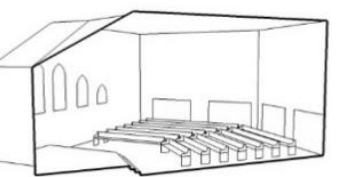

FS7: Single-sloped ceiling $\left(30^{\circ}\right)$ above sound source with flat ceiling
FS6: Single-sloped ceiling $\left(45^{\circ}\right)$ above sound source with flat ceiling

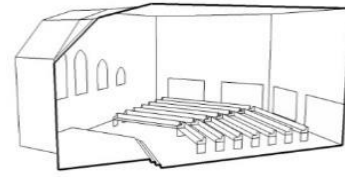

FS8: Double-sloped ceiling $\left(45^{\circ} \& 30^{\circ}\right)$ above sound source with flat ceiling

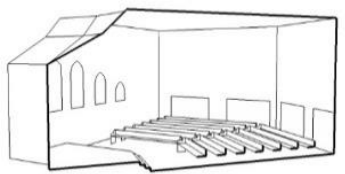

FS9: Double-sloped ceiling $\left(30^{\circ} \& 45^{\circ}\right)$ above sound source with flat ceiling

Figure 6. Different section drawings of fan-shaped room modification. 
Table 4. Speech Transmission Index (STI) for the sectional study.

\begin{tabular}{cccc}
\hline \multirow{2}{*}{ Church } & \multicolumn{3}{c}{ Speech Transmission Index, STI } \\
\cline { 2 - 4 } Original & MAX & MIN & AVR. \\
\cline { 2 - 4 } & 0.56 & 0.31 & 0.44 \\
FS1 & 0.58 & 0.32 & 0.44 \\
FS2 & 0.58 & 0.32 & 0.44 \\
FS3 & 0.57 & 0.32 & 0.44 \\
FS4 & 0.57 & 0.32 & 0.44 \\
FS5 & 0.54 & 0.30 & 0.41 \\
FS6 & 0.55 & 0.30 & 0.41 \\
FS7 & 0.55 & 0.30 & 0.41 \\
FS8 & 0.55 & 0.31 & 0.41 \\
FS9 & 0.54 & 0.32 & 0.41 \\
\hline
\end{tabular}

: Original room model result

: STI Improved

\section{CONCLUSIONS}

In this study, a series of simulations in different main shapes of contemporary churches without using sound reinforcement systems were performed. The first stage of the simulation showed that the speech intelligibility of the church was affected by the room characteristics and its ceiling profile. A series of simulation confirmed that the larger the volume is, the lower the average value of STI becomes. Simulations onto different types of ceiling shape modification revealed that ceiling profiles yield relatively improvement on the simulated STI but it has the less significant influence to show the effectiveness in the overall STI. Adequate ceiling height above the sound source and shorter distance between the sound source and its surrounding walls may provide higher speech intelligibility in most parts of the room because they can help to provide strong early sound energy reflections. Further investigations and comparative simulations on other acoustical parameters towards room characteristics are now being intensively pursued.

\section{ACKNOWLEDGEMENTS}

The authors are grateful to the Architect Ding Poi Kooi firm for providing research materials and churches drawings. The authors also would like to thank Ms. Nurul Amira and Mr. Zufar Adzahan for their continuous contribution towards this research.

\section{REFERENCES}

[1] Lee S. Comparative Analysis of Speech Intelligibility in Church Acoustics using Computer Modeling: University of Florida; 2003.

[2] Lubman D, Wetherill EA. Acoustics of worship spaces: American Institute of Physics for the Acoustical Society of America; 1985.

[3] Berry R, Kinzey Jr B. Planning for sound in church worship. Architectural Forum1954. p. 164-6.

[4] R R. Acoustics in the worship space, I, II, III, IV, VI, VII, respectively. 380 E. Northwest Highway, Suite 200, Des Plaines, IL: Diapason Magazine; 1983-1990. 
[5] Buglio JD. Why is church sound so confusing? . JdB Sound, Acoustic. Lab; 2016.

[6] Nagata. Church acoustics. Nagata Acoustics News; 2001.

[7] Brezina P. Measurement of intelligibility and clarity of the speech in romanesque churches. Journal of Cultural Heritage. 2015;16:386-90.

[8] Sygulska A. Contemporary two-storey churches - acoustic investigations. Journal of Architecture and Urbanism. 2015;39:140-8.

[9] Iannace G TA, Qandil A. The acoustics of the Catacombs. Archives of Acoustics. 2015;39:583-90.

[10] Tallon A. Acoustics at the intersection of architecture and music. Journal of the Society of Architectural Historians. 2016;75:263-80.

[11] Suárez R, Alonso A, Sendra JJ. Intangible cultural heritage: The sound of the Romanesque cathedral of Santiago de Compostela. Journal of cultural heritage. 2015;16:239-43.

[12] Elicio L, Martellotta F. Acoustics as a cultural heritage: The case of Orthodox churches and of the "Russian church" in Bari. Journal of Cultural Heritage. 2015;16:912-7.

[13] Kleiner M, Klepper DL, Torres RR. Acoustics in the Worship Spaces. Acoustics in the Worship Spaces. 1986.

[14] Berardi U. Simulation of acoustical parameters in rectangular churches. Journal of Building Performance Simulation. 2014;7:1-16.

[15] Siltanen S, Lokki T, Savioja L, Lynge Christensen C. Geometry reduction in room acoustics modeling. Acta Acustica united with Acustica. 2008;94:410-8.

[16] Christensen C, Koutsouris G. ODEON Room Acoustics Software, Version 12, User Manual. Kgs. Lyngby: Odeon A/S; 2013.

[17] Egan MD. Architectural acoustics: McGraw-Hill Custom Publishing; 1988.

[18] Barnett P, Acoustics A. Overview of speech intelligibility. Proceedings-Institute of Acoustics. 1999;21:1-16.

[19] Steeneken HJ, Houtgast T. A physical method for measuring speech-transmission quality. The Journal of the Acoustical Society of America. 1980;67:318-26.

[20] Bradley J, Sato H, Picard M. On the importance of early reflections for speech in rooms. The Journal of the Acoustical Society of America. 2003;113:3233-44. 